\title{
Correction to: Determination of trace metal concentration in compost, DAP, and TSP fertilizers by neutron activation analysis (NAA) and insights from density functional theory calculations
}

\author{
Md Sajjadur Rahman • Syed Mohammod Hossain • \\ Mir Tamzid Rahman • Mohammad A. Halim • \\ Mohammad Niaz Ishtiak • Mahbub Kabir \\ Published online: 18 December 2017 \\ (C) Springer International Publishing AG, part of Springer Nature 2017
}

Correction to: Environ Monit Assess (December 2017) 189:618 https://doi.org/10.1007/s10661-0176328-1

The original version of this article unfortunately contained an error in the body text and in Tables 4 and 6 .

The corrected version of the sentences and Tables are given below.

The online version of the original article can be found at https://doi.org/10.1007/s10661-017-6328-1.

\section{S. Rahman}

Department of Chemistry and Biochemistry, South Dakota State University, Brookings, SD 57007, USA

\section{S. M. Hossain}

Reactor and Neutron Physics Division, INST, Atomic Energy Research Establishment, Savar, GPO Box-3787, Dhaka 1000, Bangladesh

M. T. Rahman $(\bowtie) \cdot$ M. Kabir

Department of Chemistry, Jahangirnagar University, Savar, Dhaka 1342, Bangladesh

e-mail: tamzidjuchem@gmail.com

\section{A. Halim • M. N. Ishtiak}

Division of Quantum Chemistry, Green Research Centre BICCB, 38 Green Road West, Dhaka 1205, Bangladesh

\section{Results and discussion}

Page 9, under Interaction and binding of $\mathrm{Cr}, \mathrm{Sb}$, and As with DAP section, second paragraph, lines 3-6 should be rewritten as: As predicted, the binding energy, enthalpy, and the Gibbs free energy of CrO3-DAP is $-87.46,-88.06$, and $-37.17 \mathrm{kcal} / \mathrm{mol}$;

Page 10, under Interaction and binding of $\mathrm{Cr}$, $\mathrm{Sb}$, and As with DAP section, last paragraph, lines 16-18 should be rewritten as: Compared to DAP, the HOMO and LUMO energies of the $\mathrm{CrO}_{3}$-DAP, $\mathrm{Sb}_{2} \mathrm{O}_{3}$-DAP, and $\mathrm{AsO}_{3}$-DAP complexes are significantly changed.

Page 10, under Interaction and binding of $\mathrm{Cr}, \mathrm{Sb}$, and As with DAP section, last paragraph, lines 2425 should be rewritten as: And the HOMO and LUMO energies of the $\mathrm{AsO}_{3}$-DAP complex are -9.53 and $-4.07 \mathrm{eV}$ respectively with a HOMOLUMO gap of $5.46 \mathrm{eV}$.

Page 9, Title of Table 4 is corrected below.

Table 4 Selected bond distances $(\AA)$ and angles $\left(^{\circ}\right)$ of all complexes calculated at the B3LYP/SDD level of theory.

Page 10, The amended and corrected Table 6 is given in the next page. 
Table 6 Energies (eV) of HOMO, LUMO orbitals, and HOMO-LUMO gaps are calculated at the B3LYP/SDD level of theory for all complexes

\begin{tabular}{|c|c|c|c|c|c|c|c|}
\hline Molecular orbitals & $\mathrm{CrO}_{3}$ & $\mathrm{Sb}_{2} \mathrm{O}_{3}$ & $\mathrm{AsO}_{3}$ & DAP & $\begin{array}{l}\mathrm{CrO}_{3-}^{-} \\
\mathrm{DAP}\end{array}$ & $\begin{array}{l}\mathrm{Sb}_{2} \mathrm{O}_{3^{-}} \\
\text {DAP }\end{array}$ & $\begin{array}{l}\mathrm{AsO}_{3-}^{-} \\
\mathrm{DAP}\end{array}$ \\
\hline $\mathrm{LUMO}+2$ & -1.15 & -0.84 & -0.76 & 0.07 & -0.41 & 1.97 & -0.90 \\
\hline LUMO + 1 & -1.27 & -3.55 & -4.35 & -0.01 & -0.72 & -0.51 & -1.72 \\
\hline LUMO & -1.27 & -3.55 & -5.46 & -1.49 & -1.82 & -0.62 & -4.07 \\
\hline HOMO & -8.95 & -7.47 & -10.26 & -9.42 & -9.48 & -7.10 & -9.53 \\
\hline HOMO-1 & -10.09 & -7.47 & -10.35 & -9.52 & -9.55 & -7.32 & -9.62 \\
\hline HOMO-2 & -10.09 & -8.52 & -11.06 & -9.94 & -9.85 & -7.41 & -10.00 \\
\hline Gap & 7.68 & 3.92 & 4.80 & 7.93 & 7.66 & 6.48 & 5.46 \\
\hline
\end{tabular}

